\title{
Risk of tumor lysis syndrome in patients with acute myeloid leukemia treated with venetoclax-containing regimens without dose ramp-up
}

\author{
Rabia Shahswar ${ }^{1}$ (D) $\cdot$ Gernot Beutel $^{1} \cdot$ Razif Gabdoulline $^{1} \cdot$ Christian Koenecke $^{1} \cdot$ Dominik Markel $^{1} \cdot$ Matthias Eder $^{1}$. \\ Michael Stadler ${ }^{1}$ - Gudrun Gohring ${ }^{2} \cdot$ Brigitte Schlegelberger $^{2} \cdot$ Arne Trummer $^{3}$ - Juergen Krauter ${ }^{3} \cdot$ Felicitas Thol $^{1}$. \\ Michael Heuser ${ }^{1}$
}

Received: 17 June 2020 / Accepted: 9 July 2020 / Published online: 23 July 2020

(C) The Author(s) 2020

\section{To the Editor,}

The orally available BH3 mimetic venetoclax promotes apoptosis through selective inhibition of pro-survival protein B cell lymphoma 2 (BCL2) [1] and demonstrated single-agent activity and a tolerable safety profile in patients with relapsed or refractory acute myeloid leukemia (AML) [2]. Subsequent studies reported promising response rates of venetoclax combined with both low-dose cytarabine (LDAC) and hypomethylating agents (HMA) in untreated primarily elderly AML patients leading to its approval for newly diagnosed AML patients who are 75 years or older or who have comorbidities that preclude the use of intensive induction chemotherapy [3, 4]. Outside the US venetoclax is used off-label in relapsed/refractory patients with variable response rates [5]. In chronic lymphocytic leukemia (CLL), patients receive venetoclax in a weekly ramp-up dosage to mitigate the risk of tumor lysis syndrome (TLS) [6]. Despite the prophylactic use of uricostatic agents, TLS is of potential concern in venetoclax-treated AML patients, and only limited data on its clinical relevance in relapsed/refractory patients are available.

Electronic supplementary material The online version of this article (https://doi.org/10.1007/s00277-020-04181-5) contains supplementary material, which is available to authorized users.

Michael Heuser

heuser.michael@mh-hannover.de

1 Department of Hematology, Hemostasis, Oncology, and Stem Cell Transplantation, Hannover Medical School, Carl-Neuberg Straße 1, 30625 Hannover, Germany

2 Institute of Human Genetics, Hannover Medical School, Hannover, Germany

3 Department of Internal Medicine, Municipal Hospital Braunschweig, Braunschweig, Germany
We report the incidence and outcome of tumor lysis syndrome in AML patients treated with full-dose venetoclax without dose ramp-up in combination with non-intensive chemotherapy for relapsed or refractory AML $(n=40)$ or newly diagnosed AML $(n=2)$ based on data reported to our venetoclax registry. Patients aged 18 years or older with acute myeloid leukemia as defined by the World Health Organization criteria [7], who had been treated with HMA or low-dose cytarabine combined with venetoclax and were reported to the venetoclax registry (venreg.org), were included in the analysis. Venetoclax was administered at a dose of $100 \mathrm{mg}$ once daily perorally (days $1-14$, in four patients days 1-28) due to mandatory comedication with a CYP3A4-inhibitor for fungal prophylaxis. TLS was evaluated according to the Cairo-Bishop definition [8] and divided into laboratory TLS (LTLS) or clinical TLS (CTLS) (Supplementary Tables S1A and S1B). Biochemical values included potassium (hyperkalemia defined as potassium $\geq 6.0 \mathrm{mmol} / \mathrm{L}$ or $\geq 25 \%$ increase from baseline), calcium (hypocalcemia defined as calcium $\leq 1.75 \mathrm{mmol} / \mathrm{L}$ or $\geq 25 \%$ decrease from baseline), phosphate (hyperphosphatemia defined as phosphate $\geq 1.45 \mathrm{mmol} / \mathrm{L}$ or $\geq 25 \%$ increase from baseline), uric acid (hyperuricemia defined as uric acid $\geq 476 \mu \mathrm{mol} / \mathrm{L}$ or $\geq 25 \%$ increase from baseline), and creatinine (elevated creatinine levels defined as creatinine $\geq 1.5$ times greater than the institutional upper limit of normal (ULN)). Clinical manifestations included seizure and cardiac arrhythmia/sudden death. All patients had given written informed consent to the off-label use of venetoclax, genetic analysis, and the use of clinical data according to the Declaration of Helsinki and institutional guidelines. The registry was approved by the local Ethics Review Committee (ethical vote No.7972_BO_K_2018) and is registered at https://www.clinicaltrials.gov (NCT03662724).

The data cut-off for this analysis was May 21, 2020. Fortytwo patients with AML as defined by the 2016 World Health Organization criteria [7] and a median age of 65 years (range, 24-80 years) had received venetoclax (VEN) with either 
Table 1 Patient demographics and baseline characteristics of 42 AML patients with and without TLS

\begin{tabular}{|c|c|c|c|c|}
\hline Baseline characteristics & $\begin{array}{l}\text { All } \\
(n=42)\end{array}$ & $\begin{array}{l}\text { Without TLS } \\
(n=37)\end{array}$ & $\begin{array}{l}\text { With TLS } \\
(n=5)\end{array}$ & $P$ \\
\hline Age (years) & & & & 0.06 \\
\hline Median (range) & $65(24-80)$ & $68(24-80)$ & $46(26-73)$ & \\
\hline $\operatorname{Sex} n(\%)$ & & & & 0.36 \\
\hline Female & $19(45)$ & $18(49)$ & $1(20)$ & \\
\hline Male & $23(55)$ & $19(51)$ & $4(80)$ & \\
\hline Type of AML $n(\%)$ & & & & $<0.01$ \\
\hline De novo & $15(36)$ & $10(27)$ & $5(100)$ & \\
\hline Secondary & $26(62)$ & $26(70)$ & - & \\
\hline Treatment-related & & 21 & - & \\
\hline History of MDS & & 5 & - & \\
\hline Biphenotypic leukemia & $1(2)$ & $1(3)$ & - & \\
\hline ELN classification $2017 n$ (\%) & & & & 0.67 \\
\hline Favorable & $4(10)$ & $3(8)$ & $1(20)$ & \\
\hline Intermediate & $16(38)$ & $15(40)$ & $1(20)$ & \\
\hline Adverse & $21(50)$ & $18(49)$ & $3(60)$ & \\
\hline Missing & $1(2)$ & $1(3)$ & - & \\
\hline Complex karyotype $n(\%)$ & & & & 0.2 \\
\hline Yes & $13(31)$ & $13(35)$ & 0 & \\
\hline No & $27(64)$ & $22(60)$ & 5 & \\
\hline Missing & $2(5)$ & $2(5)$ & - & \\
\hline Treatment lines before VEN & & & & 0.84 \\
\hline Median (range) & $2(0-5)$ & $2(0-5)$ & $2(1-4)$ & \\
\hline WBC at start of VEN $\left(\times 10^{9} / \mathrm{L}\right)$ & & & & 0.47 \\
\hline Median (range) & $2.5(0.1-40.1)$ & $2(0.1-40.1)$ & $4.8(0.7-26.3)$ & \\
\hline Hemoglobin at start of VEN (g/dL) & & & & 0.98 \\
\hline Median (range) & $8.8(6.9-12.3)$ & $8.8(6.9-12.3)$ & $8.9(7.2-9.7)$ & \\
\hline Platelet count at start of VEN $\left(\times 10^{9} / \mathrm{L}\right)$ & & & & 0.82 \\
\hline Median (range) & $33.5(3-244)$ & $33(3-244)$ & $65(6-141)$ & \\
\hline Blasts in BM at start of VEN (\%) & & & & 0.18 \\
\hline Median (range) & $30(5-90)$ & $36(5-90)$ & $25.5(25-26)$ & \\
\hline Blasts in PB at start of VEN (\%) & & & & 0.57 \\
\hline Median (range) & $12.4(0-85)$ & $16(0-85)$ & $6(4.6-57)$ & \\
\hline AlloHCT before VEN $n(\%)$ & & & & 1.0 \\
\hline Yes & $17(40)$ & $15(40)$ & $2(40)$ & \\
\hline No & $25(60)$ & $22(60)$ & $3(60)$ & \\
\hline Previous HMA treatment $n(\%)$ & & & & 0.04 \\
\hline Yes & $28(67)$ & $27(73)$ & $1(20)$ & \\
\hline No & $14(33)$ & $10(27)$ & $4(80)$ & \\
\hline Combination partner for VEN $n(\%)$ & & & & 0.51 \\
\hline Azacitidine & $27(64)$ & $25(68)$ & $2(40)$ & \\
\hline Decitabine & $12(29)$ & $10(27)$ & $2(40)$ & \\
\hline LDAC & $3(7)$ & $2(5)$ & $1(20)$ & \\
\hline Azole treatment $n(\%)$ & & & & 0.07 \\
\hline Posaconazole & $31(74)$ & $29(78)$ & $2(40)$ & \\
\hline Voriconazole & $11(26)$ & $8(22)$ & $3(60)$ & \\
\hline Pre-treatment calcium $\mathrm{mmol} / \mathrm{L}$ & & & & 0.88 \\
\hline Median (range) & $2.15(1.73-3.28)$ & $2.14(1.73-3.28)$ & $2.16(1.93-2.39)$ & \\
\hline Pre-treatment potassium $\mathrm{mmol} / \mathrm{L}$ & & & & 0.2 \\
\hline
\end{tabular}


Table 1 (continued)

\begin{tabular}{|c|c|c|c|c|}
\hline Baseline characteristics & $\begin{array}{l}\text { All } \\
(n=42)\end{array}$ & $\begin{array}{l}\text { Without TLS } \\
(n=37)\end{array}$ & $\begin{array}{l}\text { With TLS } \\
(n=5)\end{array}$ & $\boldsymbol{P}$ \\
\hline Median (range) & $4.1(3.0-6.1)$ & $4.1(3.0-5.9)$ & $4.5(3.2-6.1)$ & \\
\hline Pre-treatment phosphate $\mathrm{mmol} / \mathrm{L}$ & & & & 0.03 \\
\hline Median (range) & $1.1(0.54-2.11)$ & $1.08(0.54-2.11)$ & $1.4(1.01-1.85)$ & \\
\hline Pre-treatment uric acid & & & & 0.38 \\
\hline Median (range) & $264(103-444)$ & $285(103-444)$ & $203(157-289)$ & \\
\hline Pre-treatment creatinine $\mu \mathrm{mol} / \mathrm{L}$ & & & & 0.01 \\
\hline Median (range) & $84.5(42-843)$ & $81(42-203)$ & $144(84-843)$ & \\
\hline
\end{tabular}

Dates are n (\%) or median (range) unless otherwise noted. ECOG Eastern Cooperative Oncology Group, $W B C$ white cell count, $B M$ bone marrow, $P B$ peripheral blood, AlloHCT allogeneic hematopoietic cell transplantation

HMA $(n=39)$ or LDAC $(n=3)$ and had clinical records about

TLS reported. The patient cohort was a high-risk cohort of relapsed $(n=18)$ and refractory $(n=22)$ patients. Two patients received VEN + HMA as frontline therapy. The analysis

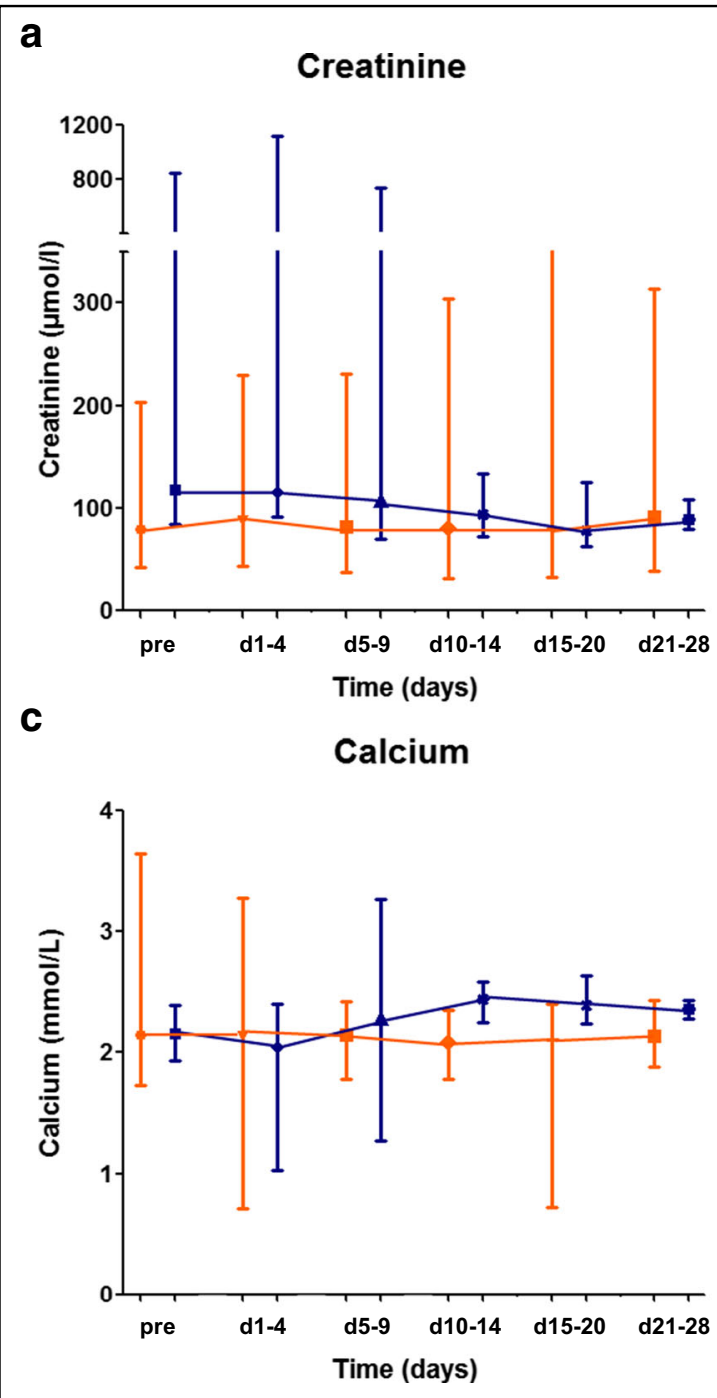

Fig. 1 Trends of TLS parameters during the first 28 days of treatment. Graphs showing changes of (a) creatinine, (b) potassium, (c) calcium, and (d) phosphate in patients without ( $n=37$, orange) and with $(n=5$, blue)

\section{b}

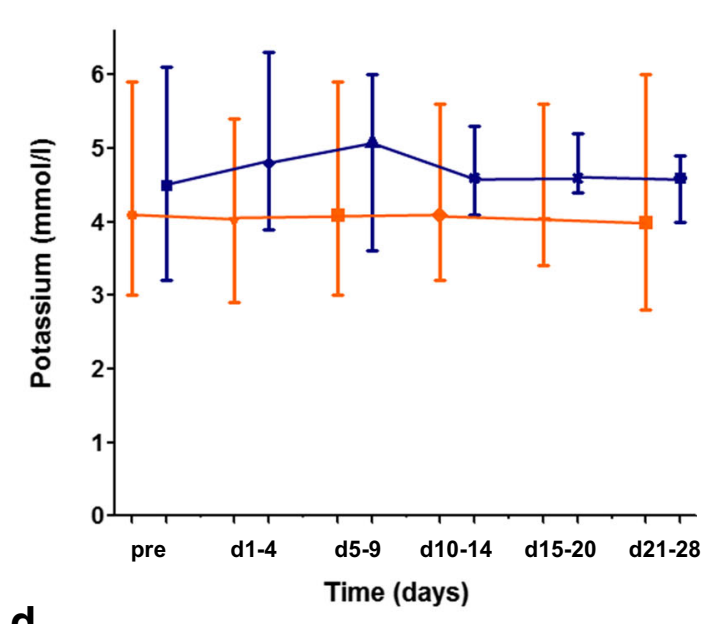

d

Phosphate

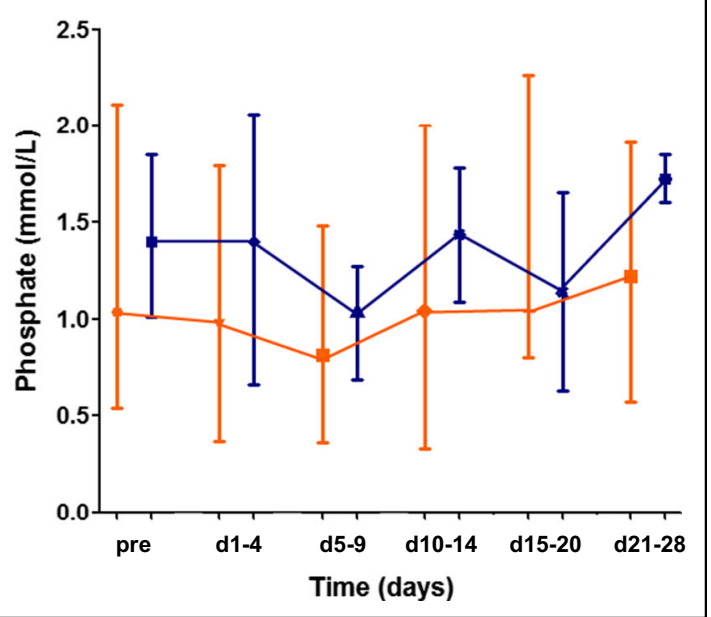

LTLS (median \pm range). Curves for patients with and without TLS are separated for better legibility of the error bars 
included 26 patients $(62 \%)$ with secondary AML and 17 patients $(40 \%)$ had received prior allogeneic stem cell transplantation. Thirteen patients $(31 \%)$ had complex cytogenetics, and $37(88 \%)$ had intermediate or poor-risk AML according to ELN 2017 criteria [9]. Overall, 5 patients developed LTLS (12\%). Among those, one patient also had elevated creatinine levels and formally met the criteria for clinical tumor lysis. However, this patient already was on dialysis for treatment of chronic end-stage renal disease due to focal segmental glomerulosclerosis before the start of venetoclax. Patients with TLS were younger, more often had de novo AML, less often had been pre-treated with HMAs, more often received voriconazole than posaconazole as antifungal agent, and had higher pre-treatment phosphate and creatinine levels than patients without TLS, while other clinical parameters were similarly distributed (Table 1).

The median day of onset of LTLS was day +2 after the start of chemotherapy (range, 0-7 days). The most frequent laboratory abnormalities were hyperkalemia $(4 / 5$, range 6.0 $6.3 \mathrm{mmol} / \mathrm{L})$, hyperphosphatemia $(3 / 5$, range $1.62-$ $2.06 \mathrm{mmol} / \mathrm{L})$, and hypocalcemia $(3 / 5$, range $1.03-$ $1.59 \mathrm{mmol} / \mathrm{L}$ ). Neither hyperuricemia nor sudden death, arrhythmia, or seizures were recorded in our cohort. Among patients developing TLS, recovery of biochemical values was mostly observed within the first 28 days of chemotherapy (Fig. 1).

The median follow-up for patients with TLS was 13.8 months and for patients without TLS 13.5 months. For patients with TLS, the overall response rate $(\mathrm{ORR}=$ complete remission $(\mathrm{CR})+$ complete remission with incomplete haematologic recovery $(\mathrm{CRi}))$ was $60 \%(n=3 / 5)$ compared with an ORR of $44 \%(n=16 / 37)$ in patients without TLS (CR/ CRi $60 \%$ vs. $44 \% ; p=0.48$ ) (Supplementary Table S2). No differences in cumulative incidence of relapse, event-free, and overall survival were observed between patients with and without TLS (Supplementary Table S2 and Supplementary Figs. S1A-C). However, these outcome data are limited by the very small cohort of patients with TLS.

Knowledge about venetoclax toxicity in AML patients has almost entirely been collected from experiences in clinical trials. In clinical trials of treatment naïve AML patients, no events of laboratory or clinical tumor lysis syndrome were observed in the combination of venetoclax plus HMA, while two cases of laboratory (not clinical) TLS were reported with the combination of LDAC plus venetoclax. However, in these trials, patients were required to have WBC count of $25 \times 10^{9} / \mathrm{L}$ or less at study initiation to mitigate any potential tumor lysis syndrome, with the use of hydroxyurea allowed in order to meet this criterion $[4,10]$.

We aimed to better understand the risk of TLS in AML patients treated with venetoclax in clinical practice and compare their outcomes with those reported in key clinical trials. In our study, venetoclax treatment in combination with LDAC or HMA without dose ramp-up induced LTLS in $12 \%$ of patients, while clinical TLS was formally observed in one dialysis patient only (2\%).

LTLS was not associated with clinical characteristics before the start of treatment. Signs of LTLS did not correlate with improved response.

Based on this retrospective analysis, a dose ramp-up for venetoclax does not appear mandatory in AML patients, even when venetoclax is combined with azole antifungals and appropriate reduction of the venetoclax dose. However, the WBC count should be lowered below $25 \times 10^{9} / \mathrm{L}$ before initiation of venetoclax. Laboratory monitoring on an outpatient basis on day 3 and day 7 after treatment starts appears sufficient in patients without pre-existing signs of TLS or renal failure and WBC below $25 \times 10^{9} / \mathrm{L}$. In conclusion, venetoclax dosing without ramp-up is clinically feasible and with consistent efficacy in AML patients even with azole co-medication.

Acknowledgments This study was supported by DFG grants HE 5240/52, HE 5240/6-1, and HE 5240/6-2 and an ERC grant under the European Union's Horizon 2020 research and innovation program (No. 638035).

Author's contribution RS, MH, and GB controlled the database. RS and MH did the statistical analysis. GB, RG, CK, DM, HE, ME, MS, GG, BS, AT, JK, and FT contributed to the analysis of clinical and biological data. $\mathrm{RS}$ and $\mathrm{MH}$ analyzed and interpreted the data and wrote the manuscript. All authors read and approved the manuscript.

Funding Information Open Access funding provided by Projekt DEAL.

\section{Compliance with ethical standards}

Conflict of interest MH reports honoraria from Novartis, Pfizer, and PriME Oncology, a consulting or advisory role for Abbvie, Bayer Pharma AG, Daiichi Sankyo, Novartis, and Pfizer, and research funding to the institution from Abbvie, Astellas, Bayer Pharma AG, BergenBio, Daiichi Sankyo, Karyopharm, Novartis, Pfizer, and Roche. All other authors declare no conflicts of interest. All authors read and agreed to the final version of the manuscript.

Open Access This article is licensed under a Creative Commons Attribution 4.0 International License, which permits use, sharing, adaptation, distribution and reproduction in any medium or format, as long as you give appropriate credit to the original author(s) and the source, provide a link to the Creative Commons licence, and indicate if changes were made. The images or other third party material in this article are included in the article's Creative Commons licence, unless indicated otherwise in a credit line to the material. If material is not included in the article's Creative Commons licence and your intended use is not permitted by statutory regulation or exceeds the permitted use, you will need to obtain permission directly from the copyright holder. To view a copy of this licence, visit http://creativecommons.org/licenses/by/4.0/.

\section{References}

1. Bhola PD, Letai A (2016) Mitochondria-judges and executioners of cell death sentences. Mol Cell 61(5):695-704. https://doi.org/10. 1016/j.molcel.2016.02.019 
2. Konopleva M, Pollyea DA, Potluri J, Chyla B, Hogdal L, Busman T, McKeegan E, Salem AH, Zhu M, Ricker JL, Blum W, DiNardo CD, Kadia T, Dunbar M, Kirby R, Falotico N, Leverson J, Humerickhouse R, Mabry M, Stone R, Kantarjian H, Letai A (2016) Efficacy and biological correlates of response in a phase II study of venetoclax monotherapy in patients with acute myelogenous leukaemia. Cancer Discov 6(10):1106-1117.4. https://doi.org/ 10.1158/2159-8290.CD-16-0313

3. Wei AH et al (2020) Venetoclax plus LDAC for patients with untreated AML ineligible for intensive chemotherapy: phase 3 randomized placebo-controlled trial. Blood. https://doi.org/10.1182/ blood.2020004856

4. DiNardo CD et al (2019) Venetoclax combined with Decitabine or Azacitidine in treatment-naive, elderly patients with acute myeloid leukemia. Blood 133(1):7-17. https://doi.org/10.1182/blood-201808-868752

5. Heuser M, Ofran Y, Boissel N, Brunet Mauri S, Craddock C, Janssen J, Wierzbowska A, Buske C (2020) Acute myeloid leukaemia in adult patients: ESMO clinical practice guidelines for diagnosis, treatment and follow-up. Ann Oncol S0923-7534(20): 36079-36078. https://doi.org/10.1016/j.annonc.2020.02.018

6. Roberts AW, Davids MS, Pagel JM, Kahl BS, Puvvada SD, Gerecitano JF, Kipps TJ, Anderson MA, Brown JR, Gressick L, Wong S, Dunbar M, Zhu M, Desai MB, Cerri E, Heitner Enschede S, Humerickhouse RA, Wierda WG, Seymour JF (2016) Targeting BCL2 with Venetoclax in relapsed chronic lymphocytic leukemia. N Eng1 J Med 374(4):311-322. https://doi.org/10.1056/ NEJMoa1513257
7. Arber DA, Orazi A, Hasserjian R, Thiele J, Borowitz MJ, le Beau MM, Bloomfield CD, Cazzola M, Vardiman JW (2016) The 2016 revision to the World Health Organization classification of myeloid neoplasms and acute leukaemia. Blood 127(20):2391-2405. https:// doi.org/10.1182/blood-2016-03-643544

8. Cairo M, Bishop M (2004) Tumour lysis syndrome: new therapeutic strategies and classification. Br J Haematol 127:3-11. https:// doi.org/10.1111/j.1365-2141.2004.05094.x

9. Döhner H, Estey E, Grimwade D, Amadori S, Appelbaum FR, Büchner T, Dombret H, Ebert BL, Fenaux P, Larson RA, Levine RL, Lo-Coco F, Naoe T, Niederwieser D, Ossenkoppele GJ, Sanz M, Sierra J, Tallman MS, Tien HF, Wei AH, Löwenberg B, Bloomfield CD (2017) Diagnosis and management of AML in adults: 2017 ELN recommendations from an international expert panel. Blood 129(4):424-447. https://doi.org/10.1182/blood-201608-733196

10. Wei AH, Strickland SA Jr, Hou JZ, Fiedler W, Lin TL, Walter RB, Enjeti A, Tiong IS, Savona M, Lee S, Chyla B, Popovic R, Salem AH, Agarwal S, Xu T, Fakouhi KM, Humerickhouse R, Hong WJ, Hayslip J, Roboz GJ (2019) Venetoclax combined with low-dose Cytarabine for previously untreated patients with acute myeloid leukemia: results from a phase Ib/II study. J Clin Oncol 37(15): 1277-1284. https://doi.org/10.1200/JCO.18.01600

Publisher's note Springer Nature remains neutral with regard to jurisdictional claims in published maps and institutional affiliations. 